einstein

Official Publication of the Instituto Israelita

de Ensino e Pesquisa Albert Einstein

ISSN: 1679-4508 | e-ISSN: 2317-6385
How to cite this article:

Nery RT, Reis AM. Development of a

Brazilian anticholinergic activity drug scale. einstein (São Paulo). 2019;17(2):eA04435. http://dx.doi.org/10.31744/einstein journal/ 2019A04435

\section{Corresponding author: \\ Adriano Max Moreira Reis \\ Avenida Antônio Carlos, 6,627 - Pampulha \\ Zip code: 31270-901 - Belo Horizonte, MG, Brazil \\ Phone: (55 31) 3409-6943 \\ E-mail: amreis@outlook.com}

Received on:

Feb 20, 2018

\section{Accepted on:}

Sep 5, 2018

Conflict of interest:

none.

\section{Copyright 2019}

\section{(cc)}

This content is licensed

under a Creative Commons

Attribution 4.0 International License.

ORIGINAL ARTICLE

\title{
Development of a Brazilian anticholinergic activity drug scale
}

\section{Desenvolvimento de uma escala brasileira de medicamentos com atividade anticolinérgica}

\author{
Raiany Thaimeny Nery', Adriano Max Moreira Reis² \\ 1 Hospital Risoleta Tolentino Neves, Belo Horizonte, MG, Brazil. \\ 2 Faculdade de Farmácia, Universidade Federal de Minas Gerais, Belo Horizonte, MG, Brazil.
}

DOI: 10.31744/einstein_journal/2019A04435

\section{ABSTRACT}

Objective: To develop a scale of anticholinergic activity drugs used in Brazil, to be applied in health care and pharmacoepidemiology research. Methods: We performed a literature review on PubMed/MEDLINE ${ }^{\circledR}$ to identify previously published scales of anticholinergic drugs. This scale started with anticholinergic drugs, and those with known anticholinergic activity as per the $4^{\text {th }}$ level, chemical-therapeutic subgroup, of the Anatomical Therapeutic Chemical classification. We also included drugs with high anticholinergic activity, as described in a list of potentially inappropriate medications for use in older adults, according to the 2015 American Geriatrics Society Beers Criteria. Drugs listed in at least two anticholinergic scales were added. Then we verified which drugs in the previous steps were marketed in Brazil. We assigned a score of 1, 2 and 3, based on their anticholinergic action. Results: A total of 273 anticholinergic drugs were identified, of which 125 were included in the scale. We identified $45(36.0 \%)$ drugs with a score of 3, 13 $(10.4 \%)$ with a score of 2 , and $67(53.6 \%)$ with a score of 1 . Drugs for the nervous and respiratory systems were the most frequent in the scale. Eight drugs were not present in previous scales. Conclusion: The methodology used for development of the Brazilian anticholinergic activity scale is simple, systematized, reproducible and easy to update. The scale allows evaluating the impact of anticholinergic burden on health outcomes, and can potentially contribute to pharmacoepidemiology research, leading to more accurate measurements of anticholinergic activity.

Keywords: Cholinergic antagonists; Anticholinergic agents; Weights and measures; Drug therapy

\section{RESUMO}

Objetivo: Desenvolver uma escala de atividade anticolinérgica abrangendo os medicamentos utilizados no Brasil, para aplicação no cuidado em saúde e em pesquisas farmacoepidemiológicas. Métodos: Realizou-se revisão da literatura no PubMed/MEDLINE ${ }^{\circledR}$ para identificação das escalas de mensuração da atividade anticolinérgica. Iniciou-se a escala com os fármacos anticolinérgicos e aqueles com atividade anticolinérgica conhecida, relacionados segundo o nível 4, subgrupo químico, na classificação da Anatomical Therapeutic Chemical. Inclúram-se os fármacos com atividade anticolinérgica alta, descritos na lista de medicamentos potencialmente inapropriados para idosos, segundo o 2015 American Geriatrics Society Beers Criteria. Adicionaram-se os medicamentos que constavam em, no mínimo, duas escalas anticolinérgicas. Em seguida, verificaram-se os medicamentos constantes nas etapas anteriores comercializados no Brasil. A magnitude da atividade anticolinérgica foi estabelecida em escores com os valores de 1, 2 e 3 . Resultados: Foram identificados 273 medicamentos com atividade anticolinérgica, sendo 125 incluídos na escala. Destes, $45(36,0 \%)$ receberam pontuação 3, $13(10,4 \%)$ tiveram pontuação 2, e $67(53,6 \%)$ pontuação 1 . A maioria dos medicamentos da escala atuava nos sistemas nervoso e respiratório. Oito fármacos não constavam em escalas prévias. Conclusão: A metodologia de desenvolvimento da escala brasileira de atividade anticolinérgica é simples, sistematizada, 
reprodutível e de fácil atualização. A escala permite avaliar o impacto da carga anticolinérgica nos resultados em saúde e pode contribuir com as pesquisas farmacoepidemiológicas, propiciando mensurações mais exatas da atividade anticolinérgica.

Descritores: Antagonistas colinérgicos; Agentes anticolinérgicos; Pesos e medidas; Tratamento farmacológico

\section{INTRODUCTION}

Drugs with anticholinergic activity are used to treat a great part of older adults, psychiatric patients, and individuals with Parkinson's disease, in addition to being used to treat several chronic and acute health conditions..$^{(1-3)}$ These drugs have an intrinsic anticholinergic activity, directly related to their chemical nature, or not related to their major therapeutic indication. ${ }^{(2,3)}$ Drugs with anticholinergic activity may have central (dizziness, nervousness, delirium and hallucinations) and peripheral (xerostomia, constipation, blurred vision and urinary retention) adverse effects. ${ }^{(4)}$

The anticholinergic burden refers to the cumulative effect of one or more drugs with anticholinergic activity. ${ }^{(2)}$ Evidence suggests that a high anticholinergic burden is associated with greater morbidity and mortality, longer lengths of stay, higher institutionalization rates, as well as functional and cognitive decline. ${ }^{(2)}$ Therefore, these drugs should be cautiously prescribed to older adults, who are more vulnerable to anticholinergic effects due to the use of multiple drugs, higher blood-brain membrane permeability, and age-related pharmacokinetic changes. ${ }^{(3)}$

Scales have been developed to be used in clinical practice to measure the anticholinergic burden of drugs and, therefore, their potential to cause adverse effects. ${ }^{(1)}$ Carnahan et al., ${ }^{(5)}$ were among the first authors to propose a scale to rate drugs based on their anticholinergic potential. These scales are based on information from expert consensus reports, anticholinergic activity data, or a combination of both. The objective measurement of the anticholinergic burden can be performed by determining the serum anticholinergic activity (SAA) of the drug and testing its muscarinic receptor affinity. ${ }^{(1)}$

Strategies to reduce the anticholinergic burden may produce considerable health benefits. ${ }^{(6)}$ Anticholinergic risk scales provide healthcare professionals with a practical tool to prevent anticholinergic adverse effects in older adults, and are important for the development of strategies to optimize drug safety..$^{(1,5)}$

Pharmacoepidemiology research is required for a better understanding of the benefits and risks of drug therapies, particularly in the elderly population. The development of implicit tools, in turn, can help guide the process of prescribing and simplifying drug schedules. ${ }^{(7)}$ Measuring exposure to anticholinergics is a method used in clinical practice and healthcare research, Investigations help understand how the anticholinergic overload can impact health outcomes, however they require appropriate methodologies and accurate measurements of exposure. ${ }^{(8)}$ The anticholinergic activity scales currently available were developed and validated in the US, Europe and Australia. ${ }^{(1,3,8)}$ However they do not comprise all drugs with anticholinergic activity, and do not account for the drugs available in different countries. $^{(1)}$

\section{OBJECTIVE}

To develop an anticholinergic activity scale comprising the drugs used in Brazil, to be applied in health care and pharmacoepidemiology research.

\section{METHODS}

Identification of anticholinergic activity rating scales A literature review was conducted on PubMed/ MEDLINE $^{\circledR}$ comprising the period between January 2006 and July 2017, using the Medical Subject Headings (MeSH) terms "cholinergic antagonists", "anticholinergic", "anticholinergic agents" and keywords "nicotinic antagonists", "muscarinic antagonists", "atropinic", "scale", "load", "burden", "risk", "exposure" and "medication". The search strategy used boolean operators $A N D$ and $O R$. The search was limited to articles in English and had the purpose of identifying anticholinergic activity rating scales.

The articles were selected by title and abstract, by two investigators. The eligible studies were subjected to a complete text analysis. The inclusion criterion was studies that featured an instrument to rate the anticholinergic burden of drugs.

A total of 11 anticholinergic scales with activity grading were identified and selected for data extraction and development of our scale: Anticholinergic Drug Scale (ADS), ${ }^{(5)}$ Anticholinergic Burden Classification $(\mathrm{ABC}),{ }^{(9)}$ Clinician-Rated Anticholinergic Score $(\mathrm{CrAS}){ }^{(10)}$ Anticholinergic Risk Scale (ARS), ${ }^{(1)}$ Serum Anticholinergic Activity (SAA), ${ }^{(12)}$ Anticholinergic Cognitive Burden Scale (ACB), ${ }^{(13)}$ Anticholinergic Activity Scale (AAS), ${ }^{(14)}$ Anticholinergic Load Scale (ACL) ${ }^{(15)}$ Anticholinergic Effect on Cognition (AEC), ${ }^{(16)}$ Muscarinic Acetylcholine Receptor ANTagonist Exposure (MARANTE) $^{(4)}$ and Anticholinergic Impregnation Scale (AIS) ${ }^{(3)}$ 
Until July 2017, three systematic reviews had been published aiming to identify anticholinergic activity rating scales, but only one of them described the scales and the associations between calculated anticholinergic burdens and clinical outcomes. ${ }^{(17)}$ The other two reviews provided tables with the name of the drugs with anticholinergic activity listed in the scales. ${ }^{(1,8)}$ Some investigations use the name Duran Scale, or Duran List, to refer to the table of 100 drugs rated as high or low activity, contained in the ADS, ${ }^{(5)} \mathrm{ABC},{ }^{(9)}$ SAA, ${ }^{(12)}$ ARS, ${ }^{(11)} \mathrm{CrAS},{ }^{(10)} \mathrm{AAS}^{(14)}$ and ACL scales, ${ }^{(15)}$ developed by the authors of the systematic review, and based on said scales. It was supplemented by a search on Martindale: the complete drug reference, ${ }^{(18)}$ to clarify any discrepancies between scale scores. ${ }^{(1,17,19)}$ A table of 195 drugs was developed based on a systematic review, which also covered the $\mathrm{ADS},{ }^{(5)} \mathrm{ABC},{ }^{(9)} \mathrm{SAA},{ }^{(12)}$ ARS, ${ }^{(11)} \mathrm{CrAS},{ }^{(10)} \mathrm{AAS}^{(14)}$ and ACL scales, ${ }^{(15)}$ however rating them into high, medium and low anticholinergic activity. This table points out the discrepant scores found in the different scales. ${ }^{\left({ }^{8}\right)}$

A table of drugs with definite, probable and possible anticholinergic effects was published during the study period, but it presented no activity grading. ${ }^{(20)}$ The Summated Anticholinergic Medications Scale (SAMS) includes only the anticholinergic drugs with high anticholinergic activity, listed in the 2012 American Geriatrics Society Beers Criteria ${ }^{(21)}$ and previous studies, and the only difference is that it states the minimum effective daily dose to calculate the anticholinergic burden. ${ }^{(22)}$ The Drug Burden index is a composite index measuring the anticholinergic and sedative burden considering the daily dose used, but with no specific list of anticholinergic drugs or activity grading. ${ }^{(23)}$

\section{Development of the anticholinergic activity rating scale}

The anticholinergic activity rating scale was developed using the following steps:

1. Preparation of a preliminary list containing the anticholinergic drugs previously listed in the $4^{\text {th }}$ level of the Anatomical Therapeutic Chemical (ATC) system. These chemical groups were described by Puustinen et al., ${ }^{(24)}$ and Brown et al., ${ }^{(25)}$ and comprise anticholinergic drugs of frequent use in clinical practice. We also included therapeutic groups comprising drugs with known anticholinergic activity. ${ }^{(2,24)}$ The codes of the chemical groups corresponding to the drugs included in this step can be found in table 1 .
2. Inclusion in the previous list of drugs with strong anticholinergic activity referenced in the 2015 American Geriatrics Society Beers Criteria. ${ }^{(26)}$

3. Addition of related drugs in at least two anticholinergic scales, with activity grading, identified in the PubMed/ MEDLINE $^{\circledR}$ search.

4. Exclusion of drugs not marketed in Brazil, after searching the products duly registered in the

Table 1. Anatomical Therapeutic Chemical (ATC) $4^{\text {th }}$ level codes of the drugs included in the first step of development of the Brazilian anticholinergic activity scale

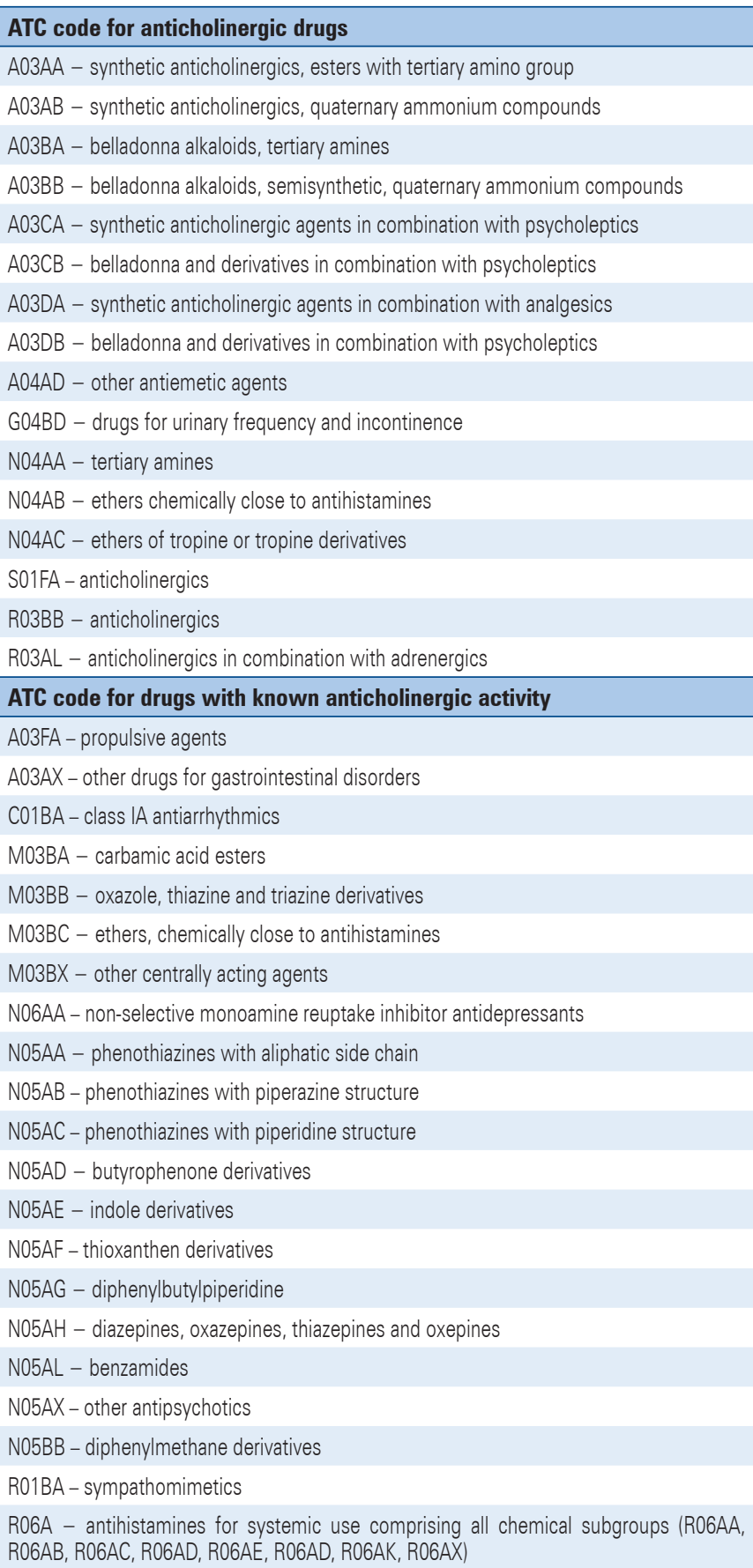


country, on the website of the Agência Nacional de Vigilância Sanitária (Anvisa). ${ }^{(27)}$

5. Exclusion of ophthalmic administration drugs, for diagnostic purposes.

6. Identification of the magnitude of the reported anticholinergic activity for each drug in the scales available. When absent, we searched the drug's anticholinergic effect profile in Martindale: the complete drug reference ${ }^{(18)}$ and assigned a score in comparison with the other drugs in the same class. The scores identified and assigned to the drugs were transformed to be used in this scale, using the system described in previous studies. ${ }^{(3,5,13)}$

6.1 Evidence of potential serum anticholinergic activity or expert-reported anticholinergic effects.

6.2 Drug with expert-reported, dose-dependent anticholinergic activity.

6.3 Anticholinergic drug or drug with known, expertreported, strong anticholinergic activity.

Drugs classified as 4 in the scale developed by Ehrt et al., ${ }^{(14)}$ were reclassified as 3 . The drugs described by Chew et al., ${ }^{(12)}$ with 0:0 and 0/+ activity were not included in the scale, and we used the following equivalence for the drugs listed by these authors: $1=+, 2=++$ and $3=+++$, to describe their anticholinergic activity.

The drugs included in the scale were rated according to the ATC classification, $5^{\text {th }}$ level, chemical substances.

\section{| RESULTS}

In the process of developing the scale, we identified 273 drugs with anticholinergic activity, of which 152 are marketed in Brazil. We excluded 25 drugs which were present in only one of the previously selected scales, and two drugs (cyclopentolate and tropicamide) intended for ophthalmic administration. A total of 125 drugs were included in the scale. Of these, 57 were identified in step 1 , of which 13 were anticholinergics and 44 had known anticholinergic activity. In step 2, we included a new drug, and 35 of the drugs found at this stage had already been included in the scale. In step 3, we included 67 drugs, of the 115 identified at this stage.

Table 2 displays the Brazilian scale of anticholinergic activity with the respective scores. Of all these drugs, $45(36.0 \%)$ were assigned a score of $3,13(10.4 \%)$ a score of 2, and $67(53.6 \%)$ a score of 1 . Considering the ATC classification, $1^{\text {st }}$ level, anatomical group, we identified that $52(41.6 \%)$ of drugs were for the nervous system, $24(19.2 \%)$ for the respiratory system, $11(8.8 \%)$ for the cardiovascular system, 11 $(8.8 \%)$ for the digestive tract and metabolism, and $11(8.8 \%)$ were for the genitourinary system and sex hormones. The analysis as per the ATC classification, $3^{\text {rd }}$ level, pharmacological subgroup, showed that antidepressants and antipsychotics accounted for the largest proportion of drugs for the nervous system.

Table 2. Brazilian scale of drugs with anticholinergic activity

\begin{tabular}{|c|c|c|c|c|c|}
\hline \multicolumn{2}{|r|}{ Score 3} & \multicolumn{2}{|r|}{ Score 2} & \multicolumn{2}{|r|}{ Score 1} \\
\hline ATC & Drug & ATC & Drug & ATC & Drug \\
\hline A03BA04 & Belladonna total alkaloids ${ }^{*}, t, a, c, e, f$ & N04BB01 & Amantadine $e^{g, i, \mathrm{n} n}$ & N03AG01 & Valproic acidd, n \\
\hline N06AA09 & Amitriptyline $e^{b, c, d, e, f, g, h, i, j, k, l, n}$ & M03BX01 & Baclofen $^{b, f, q, n}$ & N05BA12 & Alprazolam ${ }^{\mathrm{d}, \mathrm{f}, \mathrm{i}, \mathrm{n}, \mathrm{n}}$ \\
\hline A03BA01 & Atropine ${ }^{a, c, d, f, g, h, i, k, l, n}$ & N03AF01 & Carbamazepine $e^{\mathrm{d}, \mathrm{i}, \mathrm{n}}$ & J01CA01 & Ampicillin ${ }^{d, n}$ \\
\hline N04AA02 & Biperiden ${ }^{a, n}$ & A02BA01 & Cimetidine $e^{d, g, n}$ & C07AB03 & Atenolol $\left.\right|^{f, i, n}$ \\
\hline R06AB01 & Brompheniramine $e^{*}, b, c, d, i, n$ & М03ВB03 & Chlorzoxazone",b & L04AX01 & Azathioprine $e^{d, n}$ \\
\hline R06AE01 & Buclizine $^{b}$ & N05AA02 & Cetirizine $e^{f, g, k, n}$ & G02CB01 & Bromocriptine $e^{d, l, n}$ \\
\hline A03BВ01 & Butylscopolamine, bromide & N07BC02 & Levomepromazine $^{b, l, m, n}$ & N06AX12 & Bupropionf,i,n \\
\hline R06AA08 & Carbinoxamine $e^{b, c, d, i}$ & N03AF02 & Methadone $e^{f, n}$ & CO9AA01 & Captoprild, i, n \\
\hline M03BA02 & Carisoprodol" b,g & N02AB02 & Oxcarbazepine $\mathrm{d}_{\mathrm{i}, \mathrm{n}}$ & N05AN01 & Lithium carbonate ${ }^{h, k, l, n}$ \\
\hline M03ВX08 & Cyclobenzaprine $e^{b, c, g, h}$ & N05AG02 & Pethidine $^{d, i, \ldots}$ & J01DC01 & Cefoxitind, n \\
\hline R06AX02 & Cyproheptadine $e^{b, c, g, k, l, n}$ & R01BA02 & Pimozided $\mathrm{d}_{\mathrm{i}, \mathrm{l}, \mathrm{n}}$ & L04AD01 & Cyclosporine $e^{\mathrm{d}, \mathrm{n}}$ \\
\hline R06AA04 & Clemastine $e^{b, c, d, i, i}$ & R06AE07 & Pseudoephedrine $e^{*, b, g, k, n}$ & N06AB04 & Citalopram ${ }^{h, k, l, m, n}$ \\
\hline N06AA04 & Clomipramine $e^{b, c, d, e, i, l, n}$ & N05AH04 & Quetiapine $e^{b, f, j, 1, n}$ & N03AE01 & Clonazepam ${ }^{\mathrm{d}, \mathrm{k}, \mathrm{m}, \mathrm{n}}$ \\
\hline R06AB04 & Chlorpheniramine $e^{b, c, d, e, f, g, i, k, n}$ & & & N05BA02 & Chordiazepoxide", d, f, n \\
\hline N05AA01 & Chlorpromazine ${ }^{b, c, d, \text {, e }, \mathrm{f}, \mathrm{g}, \mathrm{i}, \mathrm{n}}$ & & & C03BA04 & Chlorthalidone $e^{d, i, n}$ \\
\hline N05AHO2 & Clozapine $e^{b, c, d, ~ h, i, j, 1, n}$ & & & R05DA04 & Codeine $e^{d, f, i, k, m, n}$ \\
\hline G04BD10 & Darifenacin ${ }^{a, c, d, i}$ & & & M04AC01 & Colchicine ${ }^{i, ~ n}$ \\
\hline
\end{tabular}

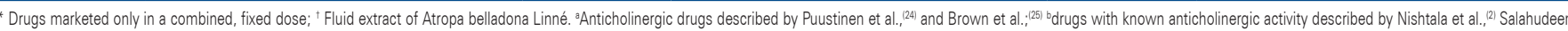

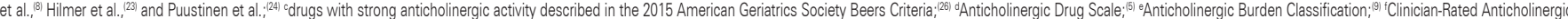

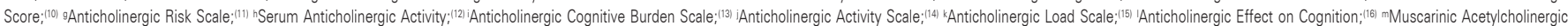
Receptor Antagonist Exposure, ${ }^{(4)}$ Anticholinergic Impregnation Scale..$^{(3)}$ 
...Continuation

Table 2. Brazilian scale of drugs with anticholinergic activity

\begin{tabular}{|c|c|c|c|c|}
\hline \multicolumn{2}{|r|}{ Score 3} & Score 2 & \multicolumn{2}{|r|}{ Score 1} \\
\hline ATC & Drug & ATC Drug & ATC & Drug \\
\hline N06AA01 & Desipramine ${ }^{b, c d, i}$ & & R06AX27 & Desloratadine ${ }^{b}$ \\
\hline R06AB06 & Dexbrompheniramine, b, c & & $\mathrm{H} 02 \mathrm{AB} 02$ & Dexamethasone $e^{\mathrm{d}, \mathrm{n}}$ \\
\hline R06AB02 & Dexchlorpheniramine ${ }^{b, c, e, k, n}$ & & N05BA01 & 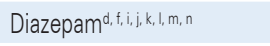 \\
\hline R06AA02 & Diphenhydramine $e^{b, c, d, f, g, i, n}$ & & C01AA05 & Digoxin $^{d, i, j, k, n}$ \\
\hline R06AA02 & Dimenhydrinate $e^{b, c, d, i, n}$ & & C08DB01 & Diltiazem $^{\mathrm{d}, \mathrm{n}}$ \\
\hline R06AA09 & Doxylamine, b, c & & B01AC07 & Dipyridamole ${ }^{\mathrm{d}, \mathrm{i}}$ \\
\hline N05AB02 & Fluphenazine $^{b, g, k, n}$ & & A03FA03 & Domperidone $e^{b, k, l, m, n}$ \\
\hline N05BB01 & Hydroxyzine $e^{b, c, d, e, g, i, n}$ & & N04BX02 & Entacaponeg, n \\
\hline A03BA03 & Hyoscyamine, a, c, d, g, h, i & & N06AB10 & Escitalopram, k, m \\
\hline A03CB04 & Homatropine $^{a, c, f}$ & & A02BA03 & Famotidine $^{\mathrm{d}, \mathrm{n}}$ \\
\hline N06AA02 & Imipramine $e^{b, c, ~ d, ~ e, ~ f, ~ g, ~ i, ~ k, ~ l, ~ n ~}$ & & N03AA02 & Phenobarbital $\left.\right|^{f, j}$ \\
\hline R03BB01 & Ipratropiuma, j, n & & N01AH01 & Fentanyld $, \mathrm{i}, \mathrm{l}, \mathrm{m}, \mathrm{n}$ \\
\hline N06AA21 & Maprotiline $e^{b, e, n}$ & & R06AX26 & Fexofenadine ${ }^{b}$ \\
\hline R06AE05 & Meclizine $^{b, c, d, g, i}$ & & N06AB03 & Fluoxetine $^{\mathrm{d}, f, \mathrm{~h}, \mathrm{k}, \mathrm{l}, \mathrm{m}, \mathrm{n}}$ \\
\hline N06AA10 & 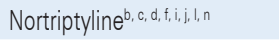 & & N06AB08 & Fluvoxamine ${ }^{\mathrm{d}, \mathrm{i}, \mathrm{k}, \mathrm{n}}$ \\
\hline N05AH03 & Olanzapine $e^{b, c, i, j}$ & & C03CA01 & Furosemide ${ }^{\mathrm{d}, \mathrm{i}, \mathrm{j}}$ \\
\hline M03BC01 & Orphenadrine ${ }^{*, b, c, d, e, i, j, l}$ & & J01GB03 & Gentamicin ${ }^{d, n}$ \\
\hline G04BD04 & Oxybutynin ${ }^{a, c, d, e, g, i, j, l, n}$ & & N05AD01 & Haloperidolb, g, i, m, n \\
\hline N06AB05 & Paroxetine $e^{c, i, j}$ & & $\mathrm{CO2DB02}$ & Hydralazine $^{d, i}$ \\
\hline R06AD02 & Promethazine $e^{b, c, d, g, i, l, n}$ & & H02AB09 & Hydrocortisone ${ }^{d, i, n}$ \\
\hline G04BD08 & Solifenacin ${ }^{a, c, n}$ & & C01DA08 & Isosorbide ${ }^{\mathrm{d}, \mathrm{i}, \mathrm{n}}$ \\
\hline N05AC02 & Thioridazine ${ }^{b, c, d, f, g, h, i, j}$ & & R06AE09 & Levocetirizine $^{b, m}$ \\
\hline R03BB04 & Tiotropiumª & & N04BA02 & Levodopa + carbidopa ${ }^{f, g, k, n}$ \\
\hline M03BX02 & Tizanidine $^{b, g, n}$ & & A07DA03 & Loperamide $^{\mathrm{d}, \mathrm{f}, \mathrm{i}, \mathrm{k}, \mathrm{m}}$ \\
\hline G04BD07 & Tolterodine $e^{a, c, d, f, ~ h, ~ i, ~, ~, ~ n ~}$ & & R06AX13 & Loratadine $^{b, f, k}$ \\
\hline N04AA01 & Trihexyphenidyla, c, d, e, f, i, j, , , n & & N05BA06 & Lorazepam $^{\mathrm{d}, \mathrm{n}}$ \\
\hline N05AB06 & Trifluoperazine $e^{b, c, g, i}$ & & $\mathrm{H} 02 \mathrm{ABO} 4$ & Methylprednisolone $e^{d, n}$ \\
\hline \multirow[t]{23}{*}{ R06AX07 } & Triprolidine $e^{b, c}$ & & A03FA01 & Metoclopramide ${ }^{b, g, k, n}$ \\
\hline & & & C07AB02 & Metoprololf, i, n \\
\hline & & & N05CD08 & Midazolam, n \\
\hline & & & N06AX11 & Mirtazapine ${ }^{g, h, ~ l, m, ~ n}$ \\
\hline & & & N02AA01 & Morphine ${ }^{d, f, i, m, n}$ \\
\hline & & & C08CA05 & Nifedipine $^{d, i, n}$ \\
\hline & & & N02AA05 & Oxycodone $e^{d, f, k, m, n}$ \\
\hline & & & J01CA12 & Piperacillin* ${ }^{*}, n$ \\
\hline & & & N04BC05 & Pramipexoleg, n \\
\hline & & & H02AB06 & Prednisolone $e^{d, 1, n}$ \\
\hline & & & $\mathrm{H} 02 \mathrm{AB} 07$ & Prednisone $e^{d, i, n}$ \\
\hline & & & A02BA02 & Ranitidine ${ }^{g, h, i, k, m, n}$ \\
\hline & & & N05AX08 & Risperidone $e^{b, f, g, i, k, m, n}$ \\
\hline & & & N04BD01 & Selegiline $e^{g, n}$ \\
\hline & & & N06AB06 & Sertraline $e^{d, f, l, n}$ \\
\hline & & & R03DA04 & Theophylline ${ }^{\mathrm{d}, \mathrm{i}, \mathrm{m}, \mathrm{n}}$ \\
\hline & & & N02AX02 & Tramadold, m, n \\
\hline & & & N02AX05 & Trazodone $e^{f, g, i, m, n}$ \\
\hline & & & H02AB08 & Triamcinolone $e^{\mathrm{d}, \mathrm{n}}$ \\
\hline & & & CO3DB02 & Triamterene ${ }^{*}, \mathrm{~d}, \mathrm{i}, \mathrm{n}$ \\
\hline & & & J01XA01 & Vancomycin $^{\mathrm{d}, \mathrm{n}}$ \\
\hline & & & B01AA03 & Warfarine $^{\mathrm{d}, \mathrm{n}}$ \\
\hline & & & N06AX16 & Venlafaxine $e^{f, k}$ \\
\hline
\end{tabular}

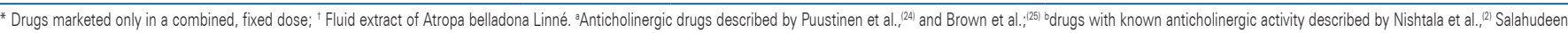

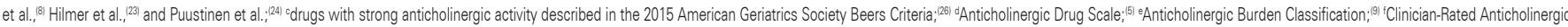

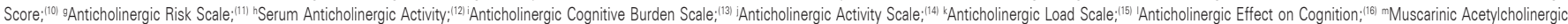
Receptor Antagonist Exposure, ${ }^{(4)}$ Anticholinergic Impregnation Scale..$^{(3)}$ 
Antihistamines for systemic use accounted for the largest proportion of drugs for the respiratory system. For the other systems, there was no predominant pharmacological subgroup.

The drugs buclizine, butylscopolamine bromide, dexbrompheniramine, doxylamine, tiotropium, tripolidine, chlorzoxazone and fexofenadine are not present in previously published scales.

\section{DISCUSSION}

The Brazilian scale of anticholinergic activity comprises the drugs available in the country and not listed in other scales, accounting for the specificities of the national market. The number of drugs is close to that of more comprehensive scales, such as the ADS, ${ }^{(5)} \operatorname{ALS}^{(15)}$ and AIS. ${ }^{(3)}$

The system applied to develop the scale is simple and allowed us to identify more drugs than a mere compilation of previous scales. Also, the scale can be easily updated through a search of the selected $4^{\text {th }}$ level ATC codes, allowing for an adaptation to the reality of the drugs registered in other countries, or inclusion of new drugs launched in Brazil. More than one third of the scale corresponds to drugs with high anticholinergic activity as per the 2015 American Geriatrics Society Beers Criteria, ${ }^{(26)}$ and therefore can be updated through a search of the latest version of said criteria.

In the scale developed, most drugs had an anticholinergic activity score of 1 . However, drugs with low anticholinergic activity must be considered, since the toxicity of anticholinergics very often results from a cumulative anticholinergic burden rather than the effect of one single drug. ${ }^{(28)}$ An Australian study of community-living elderly, with and without dementia, identified, in both groups, that level 1 drugs were the greatest contributors to the anticholinergic burden (64 to $70 \%$ ), followed by level 3 drugs (20 to $29 \%$ ) and level 2 drugs, which contributed with less than $10 \%$ of total anticholinergic burden of the population. ${ }^{(29)}$

The knowledge healthcare professionals have about potentially hazardous drugs is very limited, as well as their knowledge about drugs with anticholinergic activity. A British study showed that only $37 \%$ of healthcare professionals investigated were able to evaluate the anticholinergic burden. ${ }^{(29)}$ In view of this, having national scales to rate the anticholinergic activity of different drugs is important to optimize prescription and improve the safety of drug therapy.
Multidisciplinary and/or interdisciplinary work can contribute to decrease the number of drugs with anticholinergic activity. In a study with psychiatric patients, interventions jointly performed by physicians and pharmacists helped decrease the anticholinergic burden, leading to significantly improved memory and quality of life for patients. ${ }^{(30)}$

Measurement of the serum anticholinergic activity is expensive and not available in most healthcare services. Therefore, the development of a national anticholinergic activity scale is an useful and practical strategy for healthcare professionals, which may contribute to clinical decision-making, guiding the selection and prescription of safer drugs, helping identify patients with a greater risk of adverse reactions due to anticholinergic burden. Moreover, it contributes to pharmacoepidemiology research, providing more accurate measurements and enhancing knowledge about the impacts of anticholinergic overload on health outcomes of older adults, psychiatric patients and those with Parkinson disease. ${ }^{(4,5,11)}$

The measurement of anticholinergic activity using scales shows great variability due to the lack of consensus regarding the drugs included and the ranking of scores. The system used to develop the Brazilian scale, based on the ATC classification and therapeutic groups related with anticholinergic drugs, as well as drugs with known anticholinergic activity and high anticholinergic activity as described in the 2015 American Geriatrics Society Beers Criteria, ${ }^{(26)}$ is in line with the recommendation to standardize scales and adapt them to national markets. ${ }^{(1)}$

The Brazilian scale has limitations, since it does not include dose-related information, a recommendation already incorporated into the MARANTE scale.(4) Adding dose-related information to scales allows for a more accurate assessment of the exposure to anticholinergic drugs. The dose is important, particularly in the elderly, due to pharmacokinetic and pharmacodynamic changes related to aging. The administration route was not included either, however it is important to clarify that ophthalmic administration drugs were excluded when used for diagnostic purposes, since this does not characterize continued exposure. Another limitation is that the bibliographic search was restricted to Pubmed/MEDLINE ${ }^{\circledR}$ and the English language. However, our comprehensive search strategy allowed for identification of a large number of scales and three systematic reviews.

The validation of this scale in different healthcare settings is the next step, as well as comparison with 
the scales currently available. Other investigation perspectives must contemplate the inclusion of information on the minimum effective dose of the drugs in this scale, as well as blood-brain barrier permeability, P-glycoprotein transmembrane transport regulation, and the subtypes of receptor they act upon. It is also essential to investigate ways to standardize the scores of the drugs included in anticholinergic activity lists.

\section{CONCLUSION}

The methodology used to develop the Brazilian anticholinergic activity scale is simple and systematized. The scale of 125 drugs accounts for the specificities of the Brazilian pharmaceutical market and enables assessing the impact of anticholinergic burden of drugs on health outcomes, particularly in older adults, psychiatric patients and those with Parkinson disease. Moreover, this scale may contribute to pharmacoepidemiology research leading to more accurate measurements of anticholinergic activity.

\section{AUTHORS' INFORMATION}

Nery RT: http://orcid.org/0000-0002-4106-5850

Reis AM: http://orcid.org/0000-0002-0017-7338

\section{REFERENCES}

1. Durán CE, Azermai M, Vander Stichele RH. Systematic review of anticholinergic risk scales in older adults. Eur J Clin Pharmacol. 2013;69(7):1485-96.

2. Nishtala PS, Salahudeen MS, Hilmer SN. Anticholinergics: theoretical and clinical overview. Expert Opin Drug Saf. 2016;15(6):753-68. Review.

3. Briet J, Javelot $H$, Heitzmann E, Weiner L, Lameira C, D'Athis $P$, et al. The anticholinergic impregnation scale: Towards the elaboration of a scale adapted to prescriptions in French psychiatric settings. Therapie. 2017;72(4):427-37.

4. Klamer T, Wauters M, Azermai M, Durán C, Christiaens T, Elseviers M, et al. A novel scale linking potency and dosage to estimate anticholinergic exposure in older adults: the muscarinic acetylcholinergic receptor ANTagonist exposure scale. Basic Clin Pharmacol Toxicol. 2017;120(6):582-90.

5. Carnahan RM, Lund BC, Perry PJ, Pollock BG, Culp KR. The anticholinergic drug scale as a measure of drug-related anticholinergic burden: associations with serum anticholinergic activity. J Clin Pharmacol. 2006;46(12):1481-6.

6. Kalisch Ellett LM, Pratt NL, Ramsay EN, Barratt JD, Roughead EE. Multiple anticholinergic medication use and risk of hospital admission for confusion or dementia. J Am Geriatr Soc. 2014;62(10):1916-22.

7. Tan ECK, Sluggett JK, Johnell K, Onder G, Elseviers M, Morin L, Vetrano DL, Wastesson JW, Fastbom J, Taipale H, Tanskanen A, Bell JS; Optimizing Geriatric Pharmacotherapy through Pharmacoepidemiology Network (OPPEN) Group. Research priorities for optimizing geriatric pharmacotherapy: an international consensus. J Am Med Dir Assoc. 2018;19(3):193-9.
8. Salahudeen MS, Hilmer SN, Nishtala PS. Comparison of anticholinergic risk scales and associations with adverse health outcomes in older people. J Am Geriatr Soc. 2015;63(1):85-90.

9. Ancelin ML, Artero S, Portet F, Dupuy AM, Touchon J, Ritchie K. Nondegenerative mild cognitive impairment in elderly people and use of anticholinergic drugs: Iongitudinal cohort study. BMJ. 2006;332(7539):455-9.

10. Han L, Agostini JV, Allore HG. Cumulative anticholinergic exposure is associated with poor memory and executive function in older men. $\mathrm{J} \mathrm{Am}$ Geriatr Soc. 2008;56(12):2203-10.

11. Rudolph JL, Salow MJ, Angelini MC, McGlinchey RE. The anticholinergic risk scale and anticholinergic adverse effects in older persons. Arch Intern Med. 2008;168(5):508-13.

12. Chew ML, Mulsant BH, Pollock BG, Lehman ME, Greenspan A, Mahmoud RA, et al. Anticholinergic activity of 107 medications commonly used by older adults. J Am Geriatr Soc. 2008;56(7):1333-41.

13. Boustani M, Campbell N, Munger S, Maidment I, Fox C. Impact of anticholinergics on the aging brain: a review and practical application. Aging Health. 2008:4(3):311-20.

14. Ehrt U, Broich K, Larsen JP, Ballard C, Aarsland D. Use of drugs with anticholinergic effect and impact on cognition in Parkinson's disease: a cohort study. J Neurol Neurosurg Psychiatry. 2010;81(2):160-5.

15. Sittironnarit G, Ames D, Bush Al, Faux N, Flicker L, Foster J, Hilmer $S$, Lautenschlager NT, Maruff P, Masters CL, Martins RN, Rowe C, Szoeke C, Ellis KA; AlBL research group. Effects of anticholinergic drugs on cognitive function in older Australians: results from the AIBL study. Dement Geriatr Cogn Disord. 2011;31(3):173-8.

16. Bishara D, Harwood D, Sauer J, Taylor DM. Anticholinergic effect on cognition (AEC) of drugs commonly used in older people. Int J Geriatr Psychiatry. 2017;32(6):650-6.

17. Villalba-Moreno AM, Alfaro-Lara ER, Perez-Guerrero MC, Nieto-Martin MD, Santos-Ramos B. Systematic review on the use of anticholinergic scales in poly pathological patients. Arch Gerontol Geriatr. 2016;62:1-8. Review. Erratum in: Arch Gerontol Geriatr. 2016;64:178-80.

18. Sweetman SC. Martindale: the complete drug reference. 37a ed. London: Pharmaceutical Press; 2011. 4142 p.

19. Mayer T, Meid AD, Saum KU, Brenner H, Schöttker B, Seidling HM, et al. Comparison of Nine Instruments to calculate anticholinergic load in a large cohort of older outpatients: association with cognitive and functional decline, falls, and use of laxatives. Am J Geriatr Psychiatry. 2017;25(5):531-40.

20. Cancelli I, Beltrame M, D’Anna L, Gigli GL, Valente M. Drugs with anticholinergic properties: a potential risk factor for psychosis onset in Alzheimer's disease? Expert Opin Drug Saf. 2009;8(5):549-57. Review.

21. American Geriatrics Society 2012 Beers Criteria Update Expert Panel. American Geriatrics Society updated beers criteria for potentially inappropriate medication use in older adults. J Am Geriatr Soc. 2012;60(4):616-31. Review.

22. Gray SL, Anderson ML, Dublin S, Hanlon JT, Hubbard R, Walker R, et al. Cumulative use of strong anticholinergics and incident dementia: a prospective cohort study. JAMA Intern Med. 2015;175(3):401-7.

23. Hilmer SN, Mager DE, Simonsick EM, Ling SM, Windham BG, Harris TB, Shorr RI, Bauer DC, Abernethy DR; Health ABC Study. Drug burden index score and functional decline in older people. Am J Med. 2009;122(12):1142-9.e1-2.

24. Puustinen J, Nurminen J, Vahlberg T, Lyles A, Isoaho R, Räihä I, et al. CNS medications as predictors of precipitous cognitive decline in the cognitively disabled aged: a longitudinal population-based study. Dement Geriatr Cogn Dis Extra. 2012;2(1):57-68.

25. Brown JH, Laiken N. Agonistas e antagonistas de receptores muscarínicos. In: Brunton LL, Chabner BA, Knollman BC, editors. As Bases Farmacológicas da Terapêutica de Goodman \& Gilman. 12a ed. Rio de Janeiro: McGraw-Hill; 2012. p.219-37.

26. American Geriatrics Society (AGS). American Geriatrics Society 2015 Update Beers Criteria for Potentially Inappropriate Medication Use in Older Adults. J Am Geriatr Soc. 2015;63(11):2227-46. 
27. Brasil. Ministério da Saúde. Agência Nacional de Vigilância Sanitária (ANVISA). Consulta a medicamentos e hemoderivados [Internet]. Rio de Janeiro: ANVISA; 2018 [citado 2018 Set 4]. Disponível em: https://consultas.anvisa.gov.br/\#/ medicamentos/

28. Pfistermeister B, Tumena T, Gaßmann KG, Maas R, Fromm MF. Anticholinergic burden and cognitive function in a large German cohort of hospitalized geriatric patients. PLoS One. 2017;12(2):e0171353.
29. Mate KE, Kerr KP, Pond D, Williams EJ, Marley J, Disler P, et al. Impact of multiple low-level anticholinergic medications on anticholinergic load of community-dwelling elderly with and without dementia. Drugs Aging. 2015; 32(2):159-67.

30. Lupu AM, Clinebell K, Gannon JM, Ellison JC, Chengappa KN. Reducing anticholinergic medication burden in patients with psychotic or bipolar disorders. J Clin Psychiatry. 2017;78(9):e1270-5. 